\title{
Potential Cultivation of Koi Fish (Cyprinus Carpio) in Ciliwung River (Segmen Of Rasuna Epicentrum Superblock-Epicentrum River)
}

\author{
Deffi Ayu Puspito Sari ${ }^{1}$, Prismita Nursetyowati ${ }^{1}$, Irna Rahmaniar ${ }^{1}$ and Muh. Barid Nizarudin \\ Wajdi $^{2}$ \\ \{deffi.sari@bakrie.ac.id, baridnizar84@gmail.com\} \\ ${ }^{1}$ Environmental Engineering Program Study,Universitas Bakrie, Jl. H.R. Rasuna Said Kav. C-22, Jakarta, \\ Indonesia \\ ${ }^{2}$ STAI MiftahulUlaNganjuk, East Java Indonesia
}

\begin{abstract}
The purpose of this research are to understand Koi Fish's (CyprinusCarpio) adaptation ability to Epicentrum river water condition; to determine its adaptation time to Epicentrum river water; to determine the size of Koi fish that most potential to be planted in Epicentrum river; and to determine a simple method that potential for Koi fish cultivation in the Epicentrum river. The research was using quantitative experimental methods, three aquariums size of $100 \mathrm{~L}$ completed with water pump, filters, activated carbon, anti-ammonia stones and bio ceramic systems were used in the experiment. The first aquarium is control, the second aquarium (maximum intervention)was intervened with Epicentrum river water, extra filter, treated with $\mathrm{pH}$ control and fish medicine, while the third aquarium is only intervened with Epicentrum river water, without extra filter, $\mathrm{pH}$ control and medicine (minimum intervention). The result shows that Koi fish can live in Epicentrum river water, but require gradual conditions for Koi fish to get used to the environment; the length of time for adaptation is 3 days; Koi fish that suitable to be planted in the Epicentrum river is $6 \mathrm{~cm}-8 \mathrm{~cm}$ in size; and Koi fish can live best in condition with minimal intervention.
\end{abstract}

Keywords: activated carbon, anti-ammonia stone, bio-ceramic filter, water purification, Epicentrum River, Ciliwung River, Epiwalk

\section{Introduction}

The Epicentrum River is a river that runs along the RasunaEpicentrum superblock in South Jakarta, Indonesia. This river is actually the Ciseeng River which is a tributary of Ciliwung River.The water that flows in the Epicentrum River has undergone treatment so that its quality is much different from the original Ciseeng River. Currently Epicentrum River is inhabited by goldfish.

Epiwalk is a pedestrian area In Rasuna Epicentrum superblock. Jakarta has minimal open space for the public. Epiwalk is designed as a comfortable open space for pedestrians. Greening and the presence of clean fish ponds will certainly make the area more attractive and create the feel of a more environmentally friendly cityas released by WHO(Plouffe and Kalache, 2010). Figure 1 shows the Epicentrum River in Rasuna Epicentrum Superblock.

The nuances of sustainability in ecosystems and elements of beauty to the Epicentrum river need to be improved. The study is conducted to the extent to which Epicentrum river water can be used as a habitat for fish. Fish, as living creatures basically have the ability to adapt to the environment. Currently, in the Epicentrum river, there are parts that can be used as goldfish habitat. The challenge is to test the water quality of the Epicentrum river further. 
For that, we try to adopt more sensitive fish that is Koi fish(CyprinusCarpio).Koi fish is known as a fish that is sensitive and requires water with excellent quality for the place of its life(Twigg, 2013).

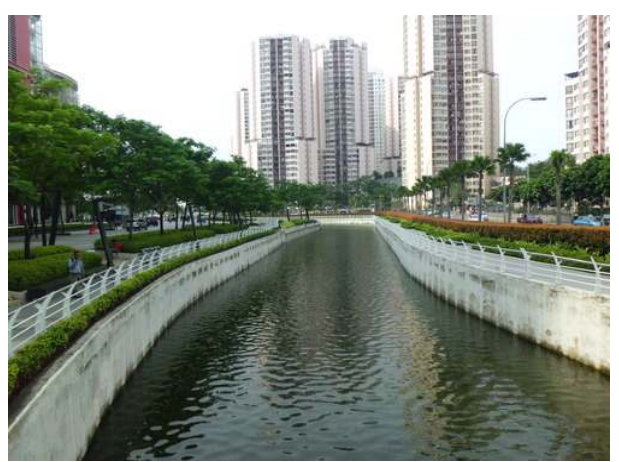

Fig. 1. The Epicentrum River.

There are two ideas on which the research is proposed. Firstly, before planting the seeds of Koi fish in the Epicentrum river, it is necessary to experiment to test the Koi fish adaptability to the original condition of Epicentrum river characteristic. The second is to find out what is the minimum but an effective treatment that can be given to Epicentrum river water to enable Koi fish to live in it. In the research methodology, description of the experimental steps to help Koi fish adapts to water conditions in the Epicentrum river is explained.

Koi fish has a beauty in terms of color and shape. Koi may have various scalepatterns and color markings thatrange from solid black to blue,red, yellow, orange, white, or anycombination and pattern of thesecolors(Watson, Hill and Pouder, 2004). However, this type of fish has a high sensitivity to be able to adapt to the new environment(Bachtiar and Lentera, 2002). Koi fish maintenance should basically follow ideal water conditions for Koi fish(Tiana, 2004). The ideal conditions for the development of Koi fish are as follows (Effendy, 1993)water temperature ranges from $24-26^{\circ} \mathrm{C}, \mathrm{pH}$ 7.2-7.4 (slightly alkaline), dissolved oxygen at least 3-5 ppm, $\mathrm{CO}_{2}$ in water max $10 \mathrm{ppm}$ and nitrite max $0.2 \mathrm{ppm}$.

Koi Fish taxonomy belongs to the Chordata philum, Actinopterygii class, Cyprinoformes order, Cyprinidae family. While the genus of Koi Fish is included in Cyprinus and is known by the name of Carpio species(Wijoyo, 2012).Among the 13 groups of koi varieties, five main classes of varieties are Kohaku, Sanke, Showa, Hirarinuji, and Kawarigoi (Effendy, 1993).

Because of the beauty of the shape and color of Koi fish, this fish is much preferred. Simply seeing the graceful motion of a Koi fish in an aquarium can eliminate or minimally reduce fatigue in daily rushing. Especially with the high price of Koi fish quality, giving pride for its owner. The price of Koi fish is expensive and the selling price of Koi fish contest winner that can reach hundreds of millions rupiah can increase the prestige of its owner(Fahriyanto, 2012).

The aims of this research are to understand Koi Fish'sadaptation ability to Epicentrum river water condition; to determine its adaptation time to Epicentrum river water; to determine the size of Koi fish that most potential to be planted in Epicentrum river; and to determine a simple method that potential for Koi fish cultivation in the Epicentrum river.

This study has scope only on the determination of simple method that is effective and efficient in terms of cost due to the presence of water treatment that already installed to purify 
Epicentrum River.The risk of this study is the potential death of Koi fish. This is an unavoidable risk considering the condition of the Epicentrum river which is far below ideal conditions for Koi fish. For that we try to test the adaptability of Koi fish by substituting the fresh water in an aquarium with Epicentrum river water. With the experiments, the minimal treatment can be given to Epicentrum river water to allow Koi fish to live in it will be understood. Koi fish cultivation potential in Epicentrum river based on Koi fish's adaptation capability and minimal treatment given to Epicentrum river water was revealed in this study.

\section{Research Method}

A preliminary experiment was conducted to test whether Koi fish were able to adapt to water with quality less than ideal for their habitats. Aquarium size of 20 liters filled with 3 Koi fish size $12 \mathrm{~cm}, 8 \mathrm{~cm}$, and $6 \mathrm{~cm}$. Twice a week the concentration of fresh water is reduced and replaced by chlorinated water that has been deposited for 2 days. Mini aerators are installed to provide oxygen supply. The average water temperature during the experiment was $28^{\circ} \mathrm{C}$. Fish are fed twice daily (morning and afternoon). This experiment was conducted without controlling the $\mathrm{pH}$ of the aquarium water. Visible observations of water look cloudy because the filtering of water relies solely on mini filters mounted on the aerator. This experiment proves that Koi fish can adapt to turbid water. This became the basis for experimenting on a larger scale, using the Epicentrum River water.

Three aquariums $100 \mathrm{~L}$ are filled with water originating from the Koi fish stock (freshwater). The aquariums were completed with pump and filter, super activated carbon, anti-ammonia stones, and bio-ceramics system. After ensuring that the aquarium pump equipment is running well then to each aquarium 20 Koi fish size average $5-6 \mathrm{~cm}$ is placed in each aquarium. The first aquarium serves as a control. The second and third aquariums are used for Koi adapted to Epicentrum river water. The second aquarium (maximum intervention)was intervened with Epicentrum river water, extra filter, treated with $\mathrm{pH}$ control and fish medicine, while the third aquarium is only intervened with Epicentrum river water, without extra filter, $\mathrm{pH}$ control and medicine (minimum intervention).All aquariums are placed in the student lounge of Bakrie University. This position is chosen so that Koi fish can get enough sunlight but not exposed too hot.

The first aquarium is an aquarium of control where water in aquariums is water that comes from Koi fish sellers and there is no addition of Epicentrum river water in this aquarium. Koi fish that live in aquarium control has maintained the condition in accordance with the conditions required to maintain the Koi fish in general.

The second and third aquariums are water-filled aquariums with additional Epicentrum water streams gradually to help Koi fish adapt to Epicentrum water. The treatment given in the second aquarium is the same as the control aquarium. We will see the difference that will occur due to the addition of Epicentrum river water to Koi fish in the second aquarium. Furthermore, the treatment in the second aquarium is called the maximum intervention.

Full intervention is described as follows; the water in this aquarium will be continuously passed through rough filters, anti-ammonia stones, super-activated carbon, bio-ceramic filters, and fine sieves. In addition, water $\mathrm{pH}$ conditions will always be maintained at the levels of 7.2 - 7.4. The air supply is filled with dropping water after passing the filter. Fish will get food supplies once a day and also additional medicines if needed.

Treatment in a third aquarium is called the minimal intervention. The water in this aquarium will be continuously circulated by being passed to a rough filter, anti-ammonia stone, super-activated carbon and bio-ceramic filter. The water $\mathrm{pH}$ conditions will not be 
regulated with the addition of chemicals. The air supply is filled with dropping water after passing the filter. Fish will get food supplies once a day but do not get additional medicines. Twice a week the quantity of water from Epicentrum river water will continue to be added. It is expected that by the end of the 15 th treatment, $95 \%$ + water in the aquarium is fully derived from the Epicentrum river.

The pattern of water addition in the second and third aquariums can be explained in Table 1. The variables that need to be recorded in each treatment are the $\mathrm{pH}$, temperature and the presence or absence of dead Koi fish and how many of those in each aquarium. This water addition pattern will adjust the observations in the field. If there is a dead koi fish, the water replacement time was expanded and the volume of water replaced was reduced. This is done in accordance with the purposes of this study; to know the adaptability of Koi fish to Epicentrum river water.

The treatment is referred to the replacement of second and third aquarium water with Epicentrum river water. It is intended to increase the concentration of Epicentrum river water in the second and third aquariums. Addition of Epicentrum river water into the second and third aquariums will continue to increase with the duration of the experiment (each interval 5 times the treatment). For example, in the second to the fifth treatment, $5 \mathrm{~L}$ of aquarium water is replaced by $5 \mathrm{~L}$ of Epicentrum water. In the sixth to 10 th treatments, $10 \mathrm{~L}$ of aquarium water is replaced by $10 \mathrm{~L}$ of Epicentrum water and so on up to $50 \mathrm{~L}$. This is done to obtain a relatively constant rate of change in concentration over time. Treatment (the addition of Epicentrum river water) was conducted every day and approximately two weeks were needed for the experiment to reach $95 \%+$ Epicentrum river water contained in the second and third aquariums.

Table 1. Water additions and water concentration differences in second and third aquariums.

\begin{tabular}{cccc}
\hline Treatment & $\begin{array}{c}\text { Epicentrum Water } \\
\text { Concentration inside } \\
\text { Aquarium }\end{array}$ & $\begin{array}{c}\text { Freshwater Concentration } \\
\text { inside Aquarium }\end{array}$ & $\begin{array}{c}\text { Volume of } \\
\text { Replaced } \\
\text { Water (L) }\end{array}$ \\
\hline 1 & 0.00 & 100.00 & 0 \\
\hline 2 & 10.00 & 90.00 & 5 \\
\hline 3 & 19.00 & 81.00 & 5 \\
\hline 4 & 27.10 & 72.90 & 5 \\
\hline 5 & 34.39 & 65.61 & 5 \\
\hline 6 & 47.51 & 52.49 & 10 \\
\hline 7 & 58.01 & 41.99 & 10 \\
\hline 8 & 66.41 & 33.59 & 10 \\
\hline 9 & 73.13 & 26.87 & 10 \\
\hline 10 & 78.50 & 21.50 & 15 \\
\hline 11 & 84.95 & 15.05 & 15 \\
\hline 12 & 89.47 & 10.53 & 15 \\
\hline 13 & 92.63 & 7.37 & 15 \\
\hline 14 & 94.84 & 5.16 & \\
\hline 15 & 96.39 & 3.61 & \\
\hline
\end{tabular}




\section{Result And Discussion}

Based on the measurements, Epicentrum river water has the following parameters:

Table 2.Epicentrum River Water Parameters.

\begin{tabular}{cccc}
\hline No & Parameter & Value & PP No. 82 Year 2001 (Class IV) \\
\hline 1 & $\mathrm{pH}$ & $7,5-11$ & $5-9$ \\
\hline 2 & Temperature & $\begin{array}{c}27,9^{\circ}-30^{\circ} \mathrm{C} \\
7,25-7,5 \\
\mathrm{mg} / 1\end{array}$ & Natural Condition \\
\hline 3 & Dissolve Oxygen & $0-3 \mathrm{mg} / 1$ & 0 \\
\hline 4 & $\mathrm{NO}_{2}$ & $0-50 \mathrm{mg} / \mathrm{l}$ & Not required \\
\hline 5 & $\mathrm{NO}_{3}$ & $0-0,8 \mathrm{mg} / \mathrm{l}$ & Not required \\
\hline 6 & $\mathrm{Cl}_{2}$ & & \\
\hline
\end{tabular}

Table 2 above shows the Epicentrum river water parameter values compared to the value of class IV water parameters based on Government Regulation No. 82 of 2001. According to the regulation, class IV is water whose designation can be used to irrigate landscaping and/or other designations that require the same water quality for that purpose. Or used also as a parameter for river water bodies. From Table 2 it can be seen that for the parameter of the temperature value, $\mathrm{NO}_{2}, \mathrm{NO}_{3}, \mathrm{GH}, \mathrm{KH}$, and $\mathrm{Cl}_{2}$ from Epicentrum river water fulfill the requirement in PP. 82 In 2001. While it is appropriate to the classification of water that can be discharged into rivers, we would like to know whether Epicentrum River water is good enough for koi fish habitat.

Epicentrum river $\mathrm{pH}(7.5-11)$ has a range up to base value. The $\mathrm{pH}$ value is affected by the state of nature and activity in the water body. The normal $\mathrm{pH}$ range for living biota in a water body is 5.5 to $10 \mathrm{pH}$ that is too low can cause the death of water biota. In accordance with the $\mathrm{pH}$ measurements in the Epicentrum River, the Epicentrum River $\mathrm{pH}$ range is eligible to be a living biota habitat, however, it is necessary to verify by experiment in the laboratory.

Dissolved Oxygen or Dissolve Oxygen (DO) Epicentrum river water is worth 7.25 - 7.5 $\mathrm{mg} / \mathrm{l}$. Dissolved oxygen is one of the important parameters in water quality assessment. The effect of waste disposal into water bodies is also influenced by the balance of oxygen values in the system. Dissolved oxygen is a regulator of the organism's metabolic activity and acts as an indicator of trophic water status (Saksena and Kaushik, 1994). Oxygen in water is generally reduced by biota respiration, decomposition of organic matter, temperature rise, inorganic substances such as hydrogen sulfide, ammonia, nitrite, iron, etc.(Sahu et al., 2000). According to the theory, dissolved oxygen in the Epicentrum river is sufficient for the standard of oxygen for fish life.

Koi fish acclimatization is done for four days. Acclimatization aims to Koi fish to adapt to the new environment. Figure 2 shows the process of acclimatization of Koi fish. In this process, 60 Koi fish are released in freshwater aquariums purchased from Koi fish sellers and did not receive the addition of Epicentrum river water. 


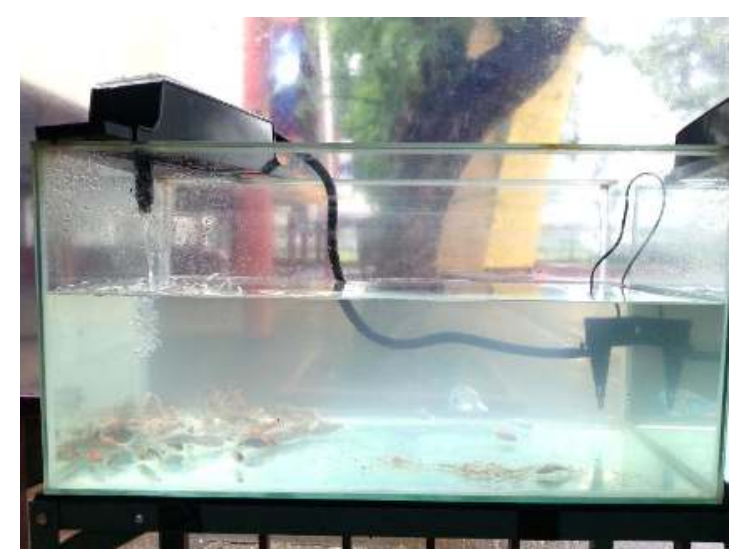

Fig. 2. Koi fish acclimatizationprocess.

Three aquariums each containing 16 Koi fish were given different treatments, namely aquarium control, an aquarium with maximum intervention and aquarium with minimal intervention. Figure 3 shows the preparation of aquarium I, II and III. Figure 4 shows the aquarium I, II and III with Koi fish and Figure 5 shows a graph of Epicentrum river water concentrations and the number of survive fish.

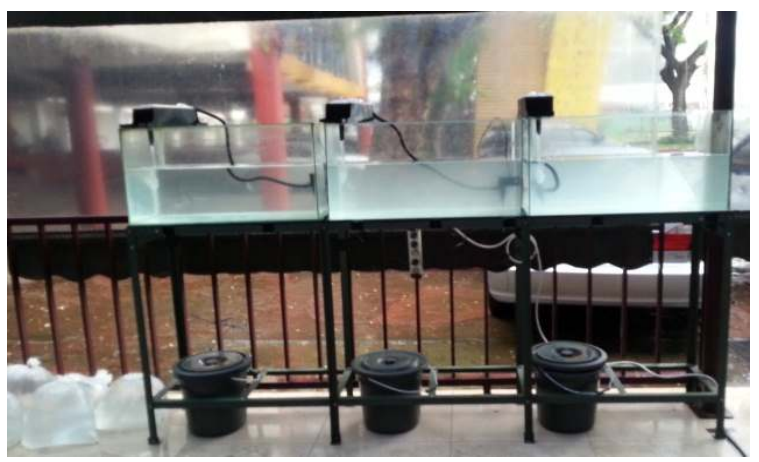

Fig. 3. Preparation of aquarium I, II and III.

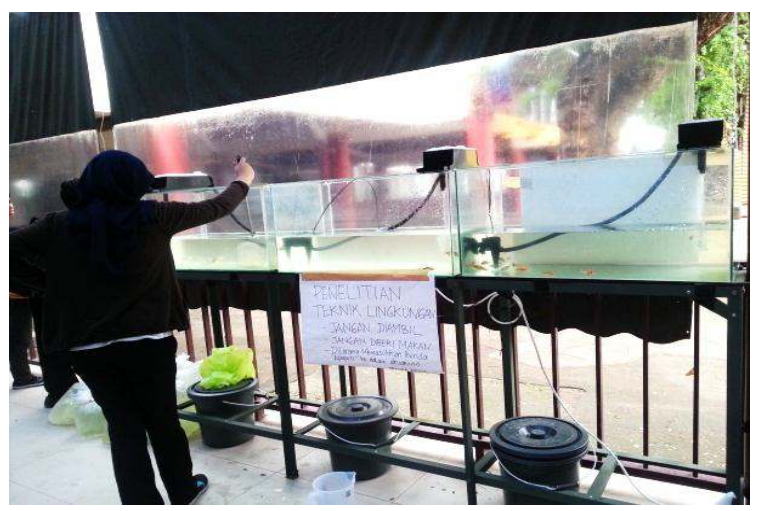

Fig. 4. First stage of experiment. 


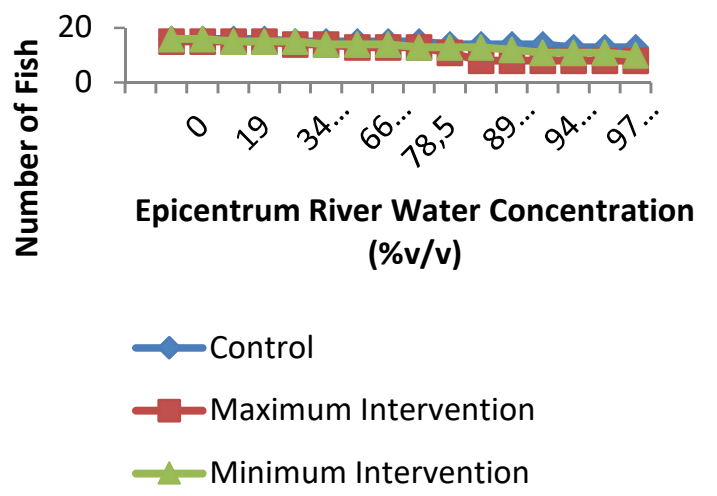

Fig. 5. Epicentrum Water Concentration and Total Number of Fish.

The figure shows that when the water concentration of Epicentrum in the aquarium is $27.1 \%$, the amount of fish in the pond starts to decrease, either at aquarium II (maximum intervention) and aquarium III (minimal intervention). Then until the concentration of Epicentrum water in the aquarium grew larger, the number of fish that lives less. On the last running day, when Epicentrum water concentration reaches $96.39 \%$, fish in the remaining control aquarium was 13, the aquarium II contains 8 Koi Fish, and fish in the aquarium III with minimum intervention remaining 10. Or at the highest Epicentrum water concentration $(93.39 \%)$, the number of fish in the aquarium I, II and III were $81.25 \%, 50 \%$ and $62,5 \%$ respectively. So that koi fish can live better in condition with minimal intervention.

\section{Conclusions}

Based on the research, the conclusions are: Koi fish can live in Epicentrum river water, but require a gradual condition for Koi fish to get used to the environment; After the aquarium water filled $96.39 \%$ of Epicentrum river water, fish living in the aquarium with maximum intervention left $56.25 \%$ of the initial conditions, whereas in the aquarium with minimum intervention contain $62.5 \%$ fish from the initial number; Adaptation time for Koi fish to adapt to Epicentrum river water is 3 days; The size of Koi fish that suitable to be planted in the Epicentrum river is $6 \mathrm{~cm}$ and $8 \mathrm{~cm}$; Koi fish can live well in condition with minimal intervention (the water was continuously circulated by being passed to a rough filter, antiammonia stone, super-activated carbon and bio-ceramic filter, without $\mathrm{pH}$ control, and additional medicines for fish, the air supply is filled with dropping water after passing the filter and fish get food supplies once a day).

\section{Acknowledgements}

This research was supported fully by the grant from Universitas Bakrie Contract No.067/UB/R/III/ 2013

\section{References}

[1] Bachtiar, I. Y. and Lentera, T. (2002) Mencemerlangkan Warna Koi. AgroMedia.

[2] Effendy, H. (1993) Mengenal Beberapa Jenis Koi. Kanisius.

[3] Fahriyanto, F. (2012) Panduan Cerdas Membuat Kolam Ikan Koi. Yogyakarta: JB 
Publisher.

[4] Plouffe, L. and Kalache, A. (2010) 'Towards global age-friendly cities: determining urban features that promote active aging', Journal of urban health. Springer, 87(5), pp. 733-739.

[5] Sahu, B. K. et al. (2000) 'Effect of pollutants on the dissolved oxygen concentration of the river Ganga at Kanpur', Pollution and biomonitoring of Indian rivers (Ed.: RK Trivedy), ABD Publication, Jaipur, India, pp. 168-170.

[6] Saksena, D. N. and Kaushik, S. (1994) 'Trophic status and habitat ecology of entomofauna of three water bodies at Gwalior, Madhya Pradesh', Perspective in entomological research (Ed.: OP Agrawal). Scientific Publishers, Jodhpur.

[7] Tiana, O. A. (2004) Membedah Rahasia Sukses Memelihara Koi. AgroMedia.

[8] Twigg, D. (2013) Buku Pintar Koi. Gramedia Pustaka Utama.

[9] Watson, C. A., Hill, J. E. and Pouder, D. B. (2004) Species profile: Koi and goldfish. Southern Regional Aquaculture Center.

[10] Wijoyo, P. M. (2012) 'Rahasia Sukses Mencegah Kematian Koi', Pustaka Agro Indonesia, Jakarta Selatan. 